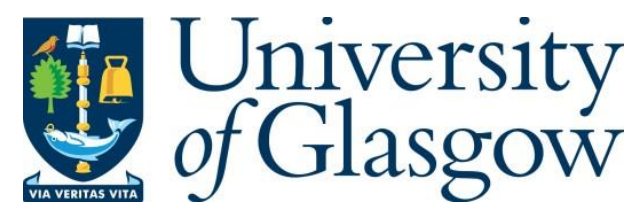

Zhou, M., Abdulghani, A. M., Imran, M. A. and Abbasi, Q. H. (2020) Internet of Things (IoT) Enabled Smart Indoor Air Quality Monitoring System. In: 2020 International Conference on Computing, Networks and Internet of Things (CNIOT 2020), Sanya, China, 24-26 Apr 2020, pp. 89-93. ISBN 9781450377713 (doi: 10.1145/3398329.3398342).

There may be differences between this version and the published version. You are advised to consult the publisher's version if you wish to cite from it.

(C) Association for Computing Machinery 2020. This is the author's version of the work. It is posted here for your personal use. Not for redistribution. The definitive Version of Record was published in Proceedings of the 2020 International Conference on Computing, Networks and Internet of Things (CNIOT 2020), Sanya, China, 24-26 Apr 2020, pp. 89-93. ISBN 9781450377713.

\title{
http://eprints.gla.ac.uk/214864/
}

Deposited on: 29 April 2020

Enlighten - Research publications by members of the University of Glasgow http://eprints.gla.ac.uk 


\section{Internet of Things (IoT) Enabled Smart Indoor Air Quality Monitoring System}

\author{
Minqiu Zhou \\ James Watt School of \\ Engineering \\ University of Glasgow \\ Glasgow, UK \\ 1158776818@qq.com
}

\author{
Amir M. Abdulghani \\ Sultan Qaboos \\ University, Oman \\ James Watt School of \\ Engineering \\ University of Glasgow \\ Glasgow, UK \\ amirmohamed.abdulgha \\ ni@glasgow.ac.uk
}

\author{
Muhammad A. Imran \\ James Watt School of \\ Engineering \\ University of Glasgow \\ Glasgow, UK \\ Muhammad.Imran@gla \\ sgow.ac.uk
}

\author{
Qammer H. Abbasi \\ James Watt School of \\ Engineering \\ University of Glasgow \\ Glasgow, UK \\ qammer.abbasi@glasgo \\ w.ac.uk
}

\begin{abstract}
This article introduces development of a system that monitors indoor air quality by using Internet of Things (IoT) technology. The objective of this system is to monitor and improve indoor air quality automatically, i.e. with minimum human intervention. The system contains physical circuit and an interactive platform. Main components used in physical circuit are Arduino Leonardo, Dust Sensor, Temperature and Humidity Sensor, LCD Display and Fan. Interactive platforms involved are The Things Network and Ubidots. Principal parameters of interest are sensed by physical circuit and converted into Air Quality Index (AQI), which is then sent to an interactive platform via gateway. After estimating AQI, the Interactive platform triggers events based on certain predetermined conditions to improve air quality through SMS alerts and circuit actuators.
\end{abstract}

\section{KEYWORDS}

Air quality monitoring, Internet of Things (IoT), Smart Home, Arduino, Air Quality Index (AQI)

\section{INTRODUCTION}

According to official EU data, more than 670,000 people in the European Union died from respiratory diseases in 2012, which accounted for $13 \%$ of all deaths in that year. The highest proportion of respiratory illnesses related deaths was in the United Kingdom (20.3\%).[1] Air pollutants are the major cause of respiratory ailments. For example, confirmed by epidemiological studies, people contract respiratory diseases more easily due to $\mathrm{PM}_{2.5}$ exposure. [2,3] From research studies, around 90\% of a person's time is spent in indoor environments, such as homes, school, offices and restaurants. [4] Therefore, indoor air quality has become a topic of extensive discussion and attention in recent years.[5]

There are many indicators that help in classifying air quality based on its properties. For example, ground-level ozone, particle pollution (also known as particulate matter) and nitrogen dioxide. Introduced in 1976, there was an Air Quality Index (API) parameter which classifies air quality in terms of 4 major pollutants, $\mathrm{SO}_{2}, \mathrm{NO}_{2}$, and $\mathrm{PM}_{10}$ concentrations. However, API was not truly representative because it did not take $\mathrm{PM}_{2.5}$ into consideration. Therefore, after January 2013, Air Quality Index (AQI) is commonly used to describe air quality and more accurate because it adds $\mathrm{PM}_{2.5}$ to calculation. [6] With the help of AQI, indoor air quality monitors could analyze air and give feedback accordingly. The Internet of Things (IoT) technology is aimed to construct a network of Internet-enabled devices, becoming a promising platform for smart home. [7] Compared with traditional communication protocols, the advantages of Long Range Wide Area Network (LoRaWAN) include relatively low power consumption, low cost, longer transmission distance and low transmission speed [8], and therefore we have used IoT technology and LoRaWAN protocol for our work presented in this paper This smart indoor air quality monitoring system includes sensors, control center and actuator as the main system components. Sensors used in this system are (i) dust sensor GP2Y1014AU and (ii) temperature \& humidity sensor DHT11. Control center is based on Arduino Leonardo, The Things Network (TTN) and Ubidots. Finally, the actuators used are fan and Ubidots SMS alert. The sensors detect and upload data to control center, and control center monitors and displays data to users on Ubidots dashboard and control actuators (fan and SMS alert process) accordingly.

\section{AQI}

The AQI is an index to present the air quality. The technical regulation on ambient AQI (on trial) was approved by the Ministry of Environmental Protection (MEP) of the People's Republic of China (PRC) on February 29, 2012.[9] Table 1 shows the AQI value and corresponding illustration. The AQI is calculated for five major air pollutants regulated by the Clean Air Act: ground-level ozone $\left(\mathrm{O}_{3}\right)$, particle pollution (also known as particulate matter) $(\mathrm{PM})$, carbon monoxide $(\mathrm{CO})$, sulfur dioxide $\left(\mathrm{SO}_{2}\right)$, and nitrogen dioxide $\left(\mathrm{NO}_{2}\right)$. There are air quality sub-indices that describe each air pollutant. The AQI value can be either calculated from five subindices or simply be the largest of the air quality sub-indices for all air pollutants. [6] In this article, the $\mathrm{PM}_{2.5}$ is the only air pollutant 
be taking into consideration. In Table 2 . air quality sub-index level of $\mathrm{PM}_{2.5}$ and corresponding air pollutant concentration are given.

\begin{tabular}{|c|c|l|}
\hline AQI & $\begin{array}{c}\text { Air } \\
\text { Quality } \\
\text { Level }\end{array}$ & \multicolumn{1}{|c|}{ Meaning } \\
\hline $0-50$ & Good & $\begin{array}{l}\text { Air quality is satisfactory, and air } \\
\text { pollution poses little or no risk. }\end{array}$ \\
\hline $51-100$ & Moderate & $\begin{array}{l}\text { Air quality is acceptable. However, } \\
\text { there may be a risk for some people, } \\
\text { particularly those who are unusually } \\
\text { sensitive to air pollution. }\end{array}$ \\
\hline $101-150$ & $\begin{array}{c}\text { Unhealthy } \\
\text { for } \\
\text { Sensitive } \\
\text { Groups }\end{array}$ & $\begin{array}{l}\text { Members of sensitive groups may } \\
\text { experience health effects. The general } \\
\text { public is not likely to be affected. }\end{array}$ \\
\hline $151-200$ & $\begin{array}{c}\text { Unhealthy } \\
\text { 20me members of the general public } \\
\text { may experience health effects; } \\
\text { members of sensitive groups may } \\
\text { experience more serious health } \\
\text { effects. }\end{array}$ \\
\hline $301-500$ & $\begin{array}{l}\text { Very } \\
\text { Unhealthy }\end{array}$ & $\begin{array}{l}\text { Health alert: The risk of health } \\
\text { effects is increased for everyone. }\end{array}$ \\
\hline
\end{tabular}

Table 1. AQI and health meaning [10]

\begin{tabular}{|l|l|l|l|l|l|l|l|}
\hline $\begin{array}{l}\text { Air Pollutant } \\
\text { Concentration } \\
\text { (ug/m3) }\end{array}$ & 35 & 75 & 115 & 150 & 250 & 350 & 500 \\
\hline $\begin{array}{l}\text { Air Quality } \\
\text { Sub-Index }\end{array}$ & 50 & 100 & 150 & 200 & 300 & 400 & 500 \\
\hline
\end{tabular}

Table 2. Air quality sub-index level of PM2.5 and corresponding air pollutant concentration [6]

\section{System analysis}

General frameworks of system are presented in Figure 1 and 2. The system is divided into physical circuit, interactive platform and communication between them, which will be discussed in coming sections.

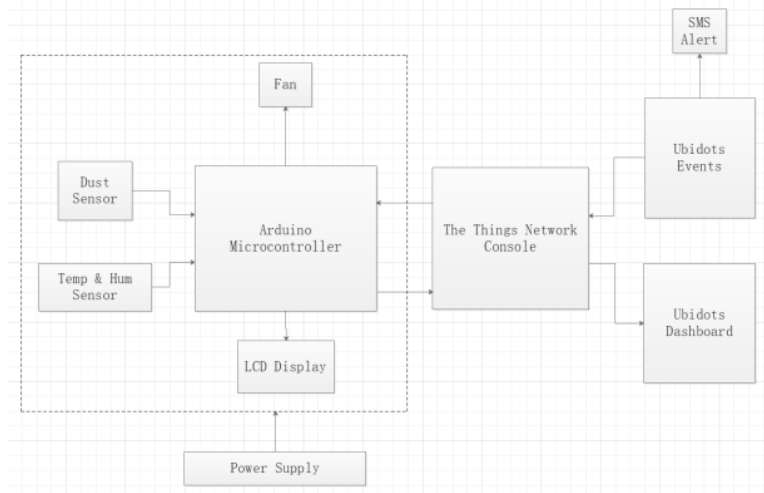

Figure 1. System Architecture
The control logic of this system is to compare data with threshold value, and trigger corresponding events when data is not within the threshold range. Fan is controlled (switched on or off) based on the dust density. SMS alert is sent when temperature or humidity is not within comfort range defined by the set parameters.

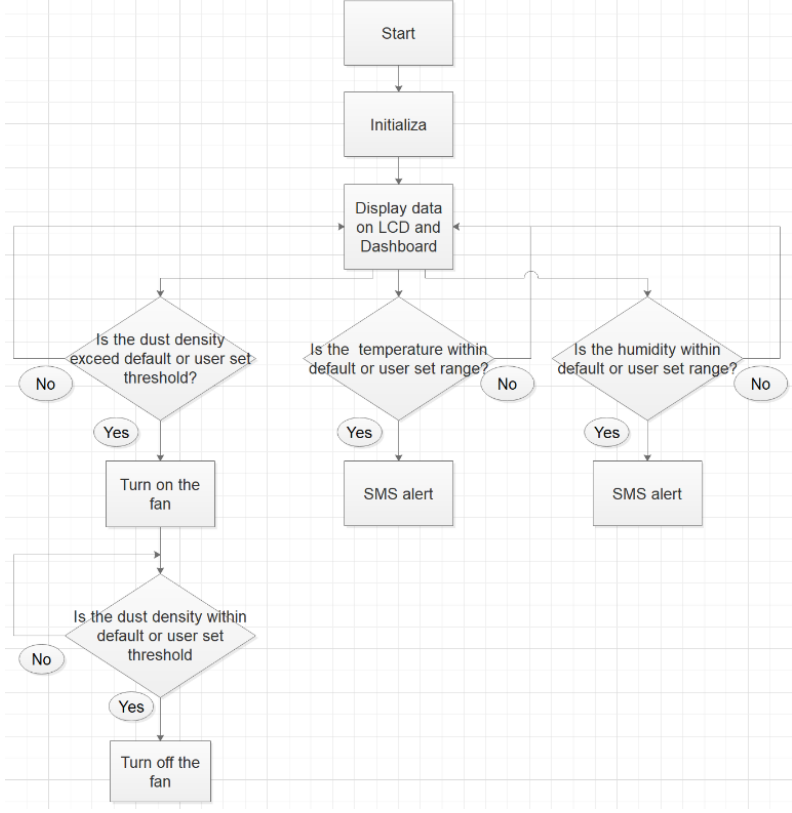

Figure 2. System Control Logic

\subsection{Physical Circuit}

Below are the components used in physical circuit:

- Microprocessor: Arduino Leonardo

- Dust sensor: GP2Y1014AU

- Temperature and humidity sensor: DHT11

- Display: LCD1602

- Logic switch: IRF9620

- Voltage regulator: LM317

- Power supply: 9V battery

- Resistors: $100 \Omega, 150 \Omega, 220 \Omega, 240 \Omega, 620 \Omega$

- Capacitors: $0.1 \mu \mathrm{F}, 1 \mu \mathrm{F}, 220 \mu \mathrm{F}$

- Potentiometer: $10 \mathrm{~K} \Omega$

Figure 3 shows diagrammatic figure of this system.

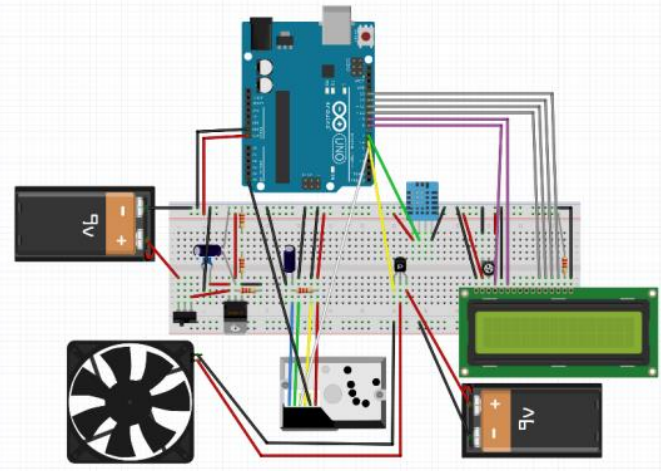

Figure 3. Physical Circuit Diagram 
Circuit schematic is presented in Figure 4.

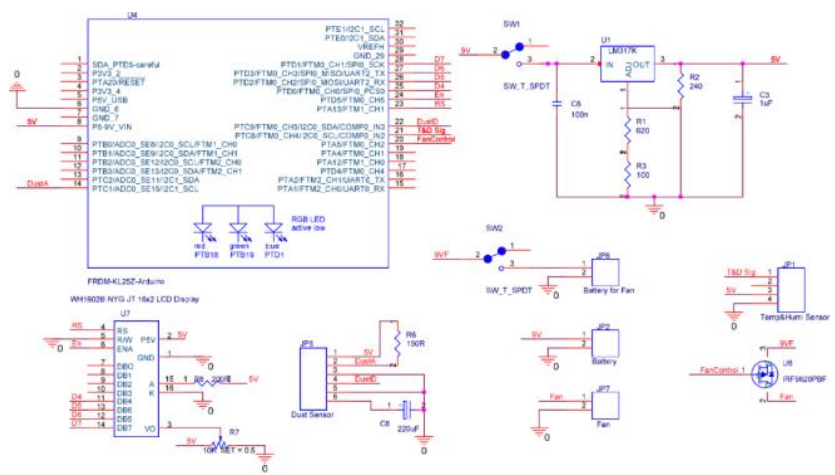

Figure 4. System Schematic

The developed actual working prototype on breadboard is illustrated in Figure 5.

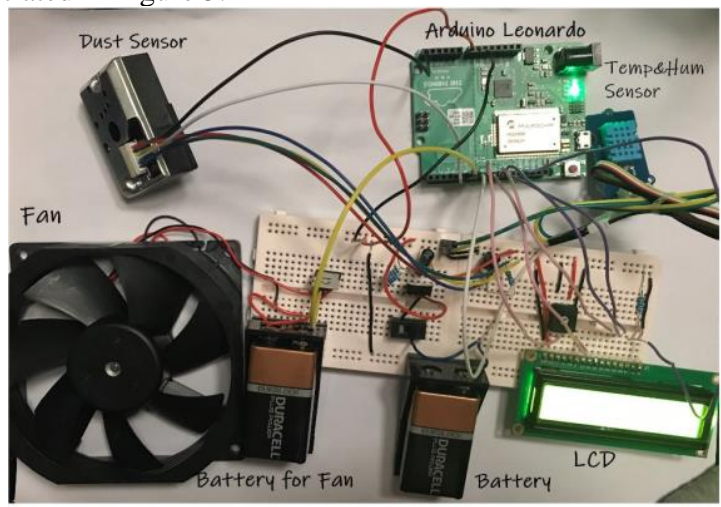

Figure 5. Developed working prototype

3.1.1 Arduino Leonardo. The microcontroller Arduino Leonardo is a task controlling part of the system. It gathers sensed data, uploads it, downloads instructions and executes instructions. Further details about communication between microcontroller and The Things Network are included in section 3.3.

3.1.2 Dust Sensor GP2Y1014AU. An infrared light-emitting diode and a phototransistor are arranged diagonally in the sensor GP2Y1014AU, allowing sensor to detect reflected light from dust in the air. The sensor has very low current consumption (up to $20 \mathrm{~mA}$, typically $11 \mathrm{~mA}$ ). The output is an analog voltage that is proportional to the measured dust concentration with a sensitivity of $0.5 \mathrm{~V} / 0.1 \mathrm{mg} / \mathrm{m}^{3}$. The minimum detected particle diameter is $0.8 \mu \mathrm{m}$, which could approximately be considered as $\mathrm{PM}_{2.5}$.

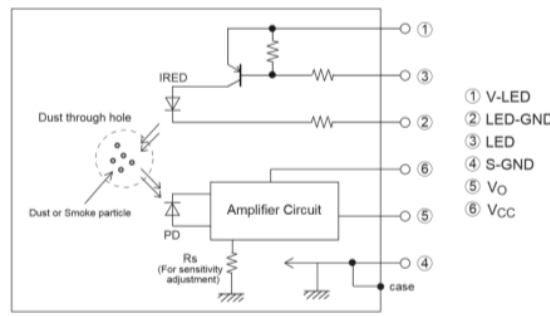

Figure 6. Internal Schematic of Dust Sensor [11]
3.1.2.1 Mathematical Analysis for Dust Sensor. According to the product specification (Figure 7.), we can obtain the expression of the output voltage Vout and the dust concentration $\mathrm{M}$ (in the case of the supply voltage of $5 \mathrm{~V}$ ):

$$
\mathrm{M}=(5 \text { Vout }-3) / 29 * 1000 \text { (unit: ug/m³) (1) }
$$

From Table 2., the fitted curve of PM2.5 concentration and air quality sub-index, or AQI in this case, is:

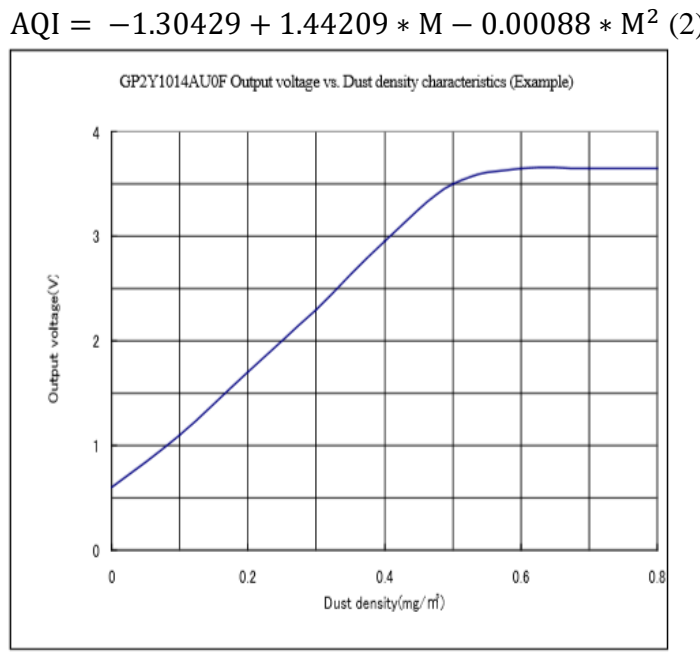

Figure 7. The output voltage VS dust density [11]

3.1.3 Logic Switch. A switching mechanism is needed to control actuators and there are different options. In this work Pmos has been used because of large drain current. IRF9620 is a Pmos in enhancement mode. By changing the voltage applied on Gate, the Drain will be connected or disconnected to Source. This Pmos is designed to control the fan.

3.1.4 Voltage Regulator. LM317 is an adjustable voltage regulator. From Figure 8, the expression of the output voltage and the resistance $\mathrm{R} 2$ is

$$
\text { Vout }=1.25(1+\mathrm{R} 2 / \mathrm{R} 1) \text {. (3) }
$$

And the power supply of Arduino Leonardo is $5 \mathrm{~V}$. Thus, by calculation, R2 $=720 \Omega$. Due to the availability of the resistance, a series connection of $620 \Omega$ and $100 \Omega$ is chosen.

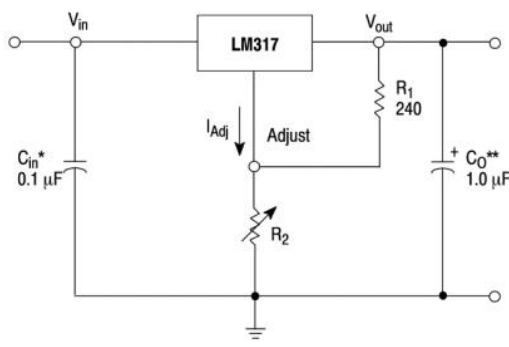

* $C_{\text {in }}$ is required if regulator is located an appreciable distance from power supply fitter. * $\mathrm{C}_{0}$ is not needed for stability, however, it does improve transient response.

$$
\mathrm{V}_{\text {out }}=1.25 \mathrm{~V}\left(1+\frac{\mathrm{R}_{2}}{\mathrm{R}_{1}}\right)+\mathrm{I}_{\text {Adj }} \mathrm{R}_{2}
$$

Since $\mathrm{I}_{\mathrm{Adj}}$ is controlled to less than $100 \mu \mathrm{A}$, the error associated with this term is negligible in most applications.

Figure 8. Standard Application of Voltage Regulator LM317 [12] 
3.2 Interactive Platform. The interactive platform for developed system includes The Things Network (TTN) and Ubidots. TTN plays a role as information transmitter. Moreover, data analysis is done by Ubidots. Sensed data is first uploaded to TTN infrastructure, then transmitted to Ubidots. The real time data is presented on the Ubidots dashboard. There are two different types of preset events, sending message to users' mobile phone and downlinking corresponding command data to TTN, which will be triggered if monitoring parameters are not in the range of predefined threshold value. After TTN is triggered, command data will be downlink to Leonardo, which actuates related components.

\subsection{Communication Between Physical Circuit and} System's Interactive Platform. The microcontroller communicates with TTN via LoRaWAN, which provides lowpower, low-data rate communication over a wide range of covered area. [8] The data transmitted between Arduino Leonardo and TTN is in the format of payload. For transmission between TTN and Ubidots, HTTP integration is used.

\section{RESULT}

This system will monitor air quality in terms of temperature, humidity and $\mathrm{PM}_{2.5}$. When temperature and humidity are beyond the pre-defined threshold value, either default or defined by users, an alert message will be sent to users' mobile phone. Furthermore, the fan will turn on when $\mathrm{PM}_{2.5}$ is greater than threshold value, and off when $\mathrm{PM}_{2.5}$ is below threshold value. On dashboard of Ubidots, real-time sensor data and data for one day are presented. Figure 9 shows the data displayed on LCD. Figure 10 depicts the triggered Ubidots event sending message to users' mobile phone.

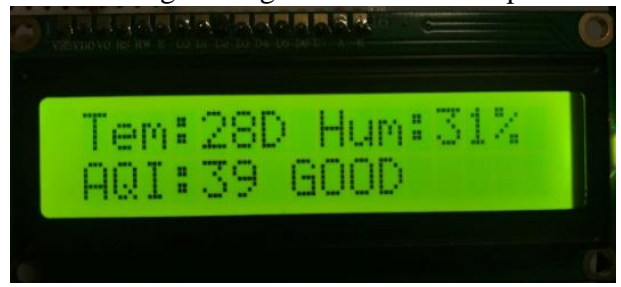

Figure 9. Result Shown on LCD

Hey there, humidity was
28.0 at $2020-03-11$
$10: 36: 07+0000$. It is
suggest to turn on the
humidifer.

Figure 10. SMS Alert of Humidity Event

Figure 11. presents complete Ubidots dashboard, where users can access data of this indoor air quality monitoring system. The AQI dial scales from 0 to 500, and different levels have different colors, which could give intuitive feedback to users. The temperature widget resembles a thermometer, and present data in digital numbers. Relative water level of tank and numerical data show relative humidity together. Different from three figures mentioned above that present real-time data, a double axis graph below them could show AQI, temperature and relative humidity of a custom time period, which enable users to check past data.

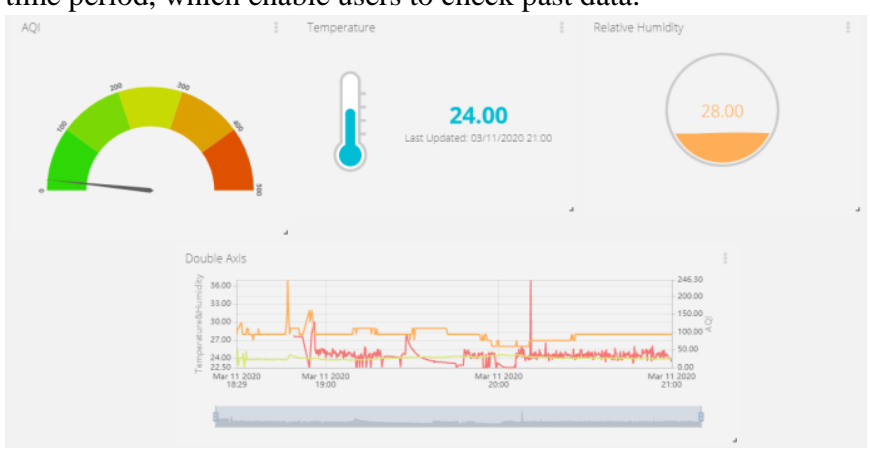

Figure 11. Designed System Dashboard

\section{Conclusion}

A smart indoor air quality monitoring system was developed and presented in this article. By using this system, users will get alerts if air quality is below the acceptable standards. This will allow users to control and improve indoor air quality, which will prevent potential respiratory illnesses and protect people who are sensitive to dirty or polluted air. In this IoT enabled system, data acquired from sensors is transmitted from Arduino Leonardo platform to TTN andthen to Ubidots wirelessly. Data is finally displayed to the users on Ubidots dashboard. Events will be triggered in case if the parameters are beyond default or user-defined threshold value(s). An alert message is sent if humidity or temperature are not within the suitable range. Command data is fetched from Ubidots through TTN to Arduino Leonardo board based on the AQI. Then microcontroller actuates components according to the downloaded command data. For further improvement, more sensors might be added to this system for gathering data related to several other air pollutants, making this system more advanced and beneficial.

\section{REFERENCES}

[1] EuroStat, "More than 670000 persons died in the EU from respiratory diseases," 109 2015. [Online]. Available: https://ec.europa.eu/eurostat/documents/2995521/6980739/3 -10092015-AP-EN.pdf/bc1e347e-9895-4131-99724ef718869c22. [Accessed 104 2020].

[2] L. Yang, C. Li and X. Tang, "The Impact of PM2.5 on the Host Defense of Respiratory System," Frontiers in Cell and Developmental Biology, vol. 8, 2020.

[3] T. Yu et al, "Wireless sensor networks for indoor air quality monitoring," Medical Engineering and Physics, vol. 35, (2), pp. 231-235, 2011; 2013;

[4] A. Andrade and F. H. Dominski, "Indoor air quality of environments used for physical exercise and sports practice: Systematic review," Journal of Environmental Management, vol. 206, pp. 577-586, 2018.]

[5] J. D. Spengler and K. Sexton, "Indoor Air Pollution: A Public Health Perspective," Science, vol. 221, (4605), pp. 9-17, 1983.

[6] S. Zheng, C. Cao and R. P. Singh, "Comparison of ground based indices (API and AQI) with satellite based aerosol products," Science of the Total Environment, vol. 488-489, 
pp. 398-412, 2014.

[7] H. Elazhary, "Internet of Things (IoT), mobile cloud, cloudlet, mobile IoT, IoT cloud, fog, mobile edge, and edge emerging computing paradigms: Disambiguation and research directions," Journal of Network and Computer Applications, vol. 128, pp. 105-140, 2019.

[8] J. Haxhibeqiri et al, "A Survey of LoRaWAN for IoT: From Technology to Application," Sensors (Basel, Switzerland), vol. 18, (11), pp. 3995, 2018.

[9] Technical Regulation on Ambient Air Quality Index (on trial), GB 3095, 29th Feb 2012.

[10] AirNow, “ AQI Basics, " [Online]. Available: https://www.airnow.gov/aqi/aqi-basics/. [Accessed date: 184 2020].

[11] Dust Sensor, GP2Y1014AU0F, Sharp, 2017 [Online]. Available:http://www.socletech.com/doc/IC\%20Channel\%20Product/SHARP_GP2Y10 14AU0F.pdf

[12] 3-Terminal Adjustable Regulator, LM317,Texas Instruments, 2016 [Online]. Available: http://www.ti.com/lit/ds/slvs044x/slvs044x.pdf 